\title{
Towards sustainable plant factories with artificial lighting (PFALs) for achieving SDGs
}

\author{
Toyoki Kozai \\ (Japan Plant Factory Association)
}

\begin{abstract}
The challenges and opportunities for developing sustainable plant factories with artificial lighting (PFALs) are discussed. After examining the production cost and productivity of existing PFALs in Japan, the possibility of introducing a relatively new concept and methodology for considerably improving productivity are discussed in relation to environmental controllability and resource use efficiencies. The fundamental and potential characteristics of ideal or next-generation PFALs (n-PFALs) are then discussed with some suggestions for actualizing n-PFALs. Finally, perspectives of the n-PFALs and technologies to be integrated into the n-PFALs are presented in relation to the Sustainable Development Goals (SDGs) to be achieved by 2030 .
\end{abstract}

Keywords: plant factory with artificial lighting (PFAL), productivity, production cost, SDGs

DOI: $10.25165 /$ j.ijabe.20191205.5177

Citation: Kozai T. Towards sustainable plant factories with artificial lighting (PFALs) for achieving SDGs. Int J Agric \& Biol Eng, 2019; 12(5): 28-37.

\section{Introduction}

Recently, there has been increasing interest in plant factories with artificial lighting (PFALs) or vertical/indoor farms. On the other hand, people often complain about the high production costs of PFAL-grown vegetables, and the social role of PFALs.

The major components of the production cost of existing PFALs are depreciation (initial investment), labor (working hours) and electricity costs. Since around 2016, the monetary (sales/costs), working hours ( $\mathrm{kg}$ of produce/h) and electricity ( $\mathrm{kg}$ of produce $/ \mathrm{kW} \cdot \mathrm{h}$ ), and cultivation area and time ( $\mathrm{kg}$ of produce per unit cultivation area and unit time) productivities for leaf lettuce in Japan have improved considerably in many PFALs. These recent improvements in productivity are the result of introducing LEDs, robotic/automated units, improved cultivation units with production management software and increased public acceptance. A similar trend is observed in several other countries.

However, even in improved PFALs in Japan, recent advanced technologies such as artificial intelligence (AI), the Internet of Things (IoT), continuous plant traits measurement (phenotyping), solar cells with batteries, and breeding using DNA markers, etc. are rarely implemented.

The next-generation PFAL (n-PFAL) to be developed by integrating the above advanced technologies will considerably improve productivity. Then, the n-PFAL is expected to solve many of today's interrelated social and economic issues concerning functional foods, the environment, resources and quality of life amid the increase in urban population, decrease in agricultural population, arable/fertile land area and water availability, and the changing, vulnerable climate ${ }^{[1]}$. The n-PFAL is expected to enhance local production for local consumption, and reduces food mileage, loss of fresh produce due to damage during transportation and storage, and fossil fuel consumption for transportation by cars,

Received date: 2019-04-08 Accepted date: 2019-07-05

Biographies: Toyoki Kozai, $\mathrm{PhD}$, Professor, research interest: plant factory with artificial lighting. Japan Plant Factory Association, Japan. Tel: +81-4-7137-8114, Email: kozai@faculty.chiba-u.jp. and so will play a significant role in achieving a substantial portion of the 17 Sustainable Development Goals (SDGs) to be achieved by $2030^{[2]}$.

This paper describes the main viewpoints, challenges and opportunities for developing n-PFALs for achieving some of the SDGs, while noting that we are still at the initial technological and scientific stages of the n-PFAL. First, the production cost and productivity of existing PFALs in Japan are examined. Then, the possibility of introducing a relatively new concept and methodology for considerably improving productivity are discussed in relation to environmental controllability and resource use efficiencies. Furthermore, the fundamental and potential characteristics of ideal or n-PFALs are discussed with some suggestions for actualizing n-PFALs. Finally, perspectives of the n-PFALs and technologies to be integrated into the n-PFALs are presented.

\section{Production costs and productivities of existing PFALs}

\subsection{Definition of PFAL}

This paper discusses PFALs satisfying the following six conditions. This type of PFAL has been used in Japan mainly for producing leafy vegetables for sale on a large scale. All the numerical data given in the following sections were obtained from PFALs satisfying these six conditions.

(1) All walls and roofs are optically opaque, and only the light emitted by lamps is used as the light source in the cultivation room.

(2) The cultivation room is nearly airtight under standard operating conditions.

(3) The walls and floor are thermally well insulated.

(4) A hydroponic cultivation unit is used.

(5) Workers wearing disinfected clothing only can enter the cultivation room (sanitary area) through an air shower room.

(6) The propagation and growth of pathogens, insects and small animals is strictly monitored, recorded and kept to minimum levels.

One of the differences between the PFAL and indoor/vertical 
farms is that PFALs use lamps as the sole light source. In contrast, indoor farms often include an indoor plant cultivation space using solar light transmitted through glass windows, and vertical farms often include rooftop greenhouses that use solar light.

Figure 1 shows the main environmental characteristics of the existing PFAL for commercial production. The cultivation room is highly but not completely airtight; minimum air infiltration is necessary to avoid the accumulation of volatile organic compounds (VOC) and other gases toxic to plants in the cultivation room. Organic acids and aromatic substances are sometimes emitted from the roots to the nutrient solution. Propagation of algae in the cultivation beds and wet surfaces in the cultivation room needs to be minimized.

\begin{tabular}{|l|l|l|}
\hline a) Highly & No invasion of insects and dusts \\
\hline airtight & Recycling use of water and $\mathrm{CO}_{2}$ \\
\hline Cinimum air infiltration to avoid $\mathrm{VOC}^{*}$ accumulation \\
\hline C) Thermally \\
\hline insulated
\end{tabular}

Note: *VOC: Volatile Organic Compounds, **VPD: Vapor Pressure Deficit, ***RFD: Photon Flux Density.

Figure 1 Main environmental characteristics of the existing PEAL

The following conditions are desirable, but not mandatory, for PFALs:

(1) Water vapor transpired from plants is condensed and collected at the cooling panels of air conditioners, and is recycled for irrigation or other purposes.

(2) The nutrient solution is sterilized through a biofilter, micro-porous/membrane filter, ultraviolet light, and/or ozone gas before being recycled for use.

(3) Plants harvested and packed in the cultivation room (sanitary area) are taken out through a double-door pass-box, and supplies are brought into the cultivation room through the double-door pass-box.

Only inorganic fertilizer is supplied to the cultivation beds. (Inorganic fertilizer can be made by decomposing organic fertilizer to make it inorganic with the presence of microorganisms, if the user prefers $)^{[3]}$. It should be noted that any green-colored plants containing chlorophylls in leaves can grow photoautotrophically without absorbing any organic nutrients from the roots, although the plants absorb small amounts of organic nutrients such as amino acids, vitamins and sugars (glucose, fructose, etc.) existing around the roots.

\subsection{Production costs}

The annual average percentages of depreciation (or initial investment), labor (or working hours) and electricity costs and profit to annual sales in a PFAL for commercial production in Japan are, respectively, $26 \%, 21 \%, 18 \%$ and $11 \%$; the rest being consumables $(6 \%)$, logistics $(5 \%)$, seeds $(2 \%)$ and others $(11 \%)^{[4,5]}$. Thus, reductions in these three major cost components are critical to reduce the total production cost.

\subsection{Resource and monetary productivities ${ }^{[5]}$}

Resource productivities with respect to cultivation area and time, working hours (labor) and electricity are estimated to be, respectively, $0.25-0.33 \mathrm{~kg} / \mathrm{m}^{2} \cdot \mathrm{d}$ ( or $91 \mathrm{~kg} / \mathrm{m}^{2} \cdot \mathrm{a}$ ), 7.7-10.0 $\mathrm{kg} / \mathrm{h}$ and $0.11-0.14 \mathrm{~kg} / \mathrm{kW} \cdot \mathrm{h}$ as of 2018 for leaf lettuce production in existing
PFALs in Japan (Cultivation area and time productivity can be converted to cultivation space productivity in units of $\mathrm{kg} / \mathrm{m}^{3} \cdot \mathrm{d}$, if necessary).

Monetary productivities (monetary ratio of sales to cost) of cultivation area and time, working hours, electricity and all other resources are estimated to be 0.41-0.55, 0.50-0.59, 0.55-0.64 and $0.52-0.70 \mathrm{~kg} /$ Euro, respectively. Overall monetary productivity (monetary ratio of annual total sales to annual total cost) is 0.14-0.19 kg/Euro.

\subsection{Practical ways to improve the productivities within around 5 years ${ }^{[5]}$}

1) Electricity productivity

The electricity consumption for lighting accounts for $75 \%-80 \%$ of total electricity consumption in the cultivation room ${ }^{[3,6]}$. There are roughly 3 ways to improve the electricity productivity in terms of lighting ${ }^{[7]}$ : 1) Use LEDs with high photosynthetic photon number efficacy (or electric energy-photosynthetic photon conversion coefficient). Recently, the efficacy of over $3 \mathrm{mmol} / \mathrm{J}$ is on the market ${ }^{[5,8]}$;2) Improve the percentage of photosynthetic photons received by leaves to those emitted by LEDs, by using light reflectors inside the cultivation space and so forth. It should be noted that about $30 \%$ of photosynthetic photons is not received by leaves, and hits uselessly the cultivation panels, floor, wall, etc.; and 3) Improve the photosynthetic photon yield (ratio of photosynthetic photons fixed as chemical energy in leaves to those absorbed by leaves) by controlling aerial and rootzone environments, cultivar selection and/or cultivation methods.

Electricity productivity of air conditioners are affected by the coefficient of performance (COP) and that of water pumps, etc. are affected by their power factors ${ }^{[3]}$.

2) Working hour productivity

In many medium-scale PFALs in Japan, transplanting, harvesting, packing, packaging, cultivation panel washing/cleaning and floor cleaning are still conducted manually, although seeding is automated or semi-automated in most PFALs. On the other hands, recently, in large-scale PFALs, transplanting, packing, packaging, transportation of produce from cultivation room to packaging room, cultivation panel washing, labelling and shipping are mostly automated, although harvesting and preparation for packing (removing yellowed and damaged leaves and root separation from the aerial part of plants) are still conducted manually. The above automation improved the working hour productivity probably by $30 \%-40 \%$, while increased the initial investment significantly.

It is expected in the near future that no person enters the cultivation room of a large scale PFAL except for periodic maintenance and emergency measure, and that over $90 \%$ of handling operations is automated. Then, the working hour productivity will be improved substantially.

3) Cultivation area and time productivity

The cultivation and time productivity are affected by many factors including the type and characteristics of cultivation system, production scheduling and operation, aerial and rootzone environments, skill and motivation of workers, efficiency of Plan-Do-Check-Act/Adjust (PDCA) Cycle, and so forth. The production scheduling and operation includes decision making on the dates and time of seeding, spacing/transplanting and harvesting, human and material resource allocation. At present, there is no general theory to improve the cultivation area and time productivity. However, there is a high potential to improve it substantially.

2.5 Required improvement of overall monetary productivity

The overall monetary productivity of advanced PFALs is 
expected double in the near future (perhaps by around 2025) compared with existing PFALs in Japan, simply by changing the setpoints of environmental factors, using robotic systems, optimizing production process control, improvements of cultivation system and method, and so forth.

On the other hand, the monetary productivity of PFALs needs to be more than tripled compared with existing PFALs to make a profit by growing fruit vegetables such as tomato, and berries such as strawberry, raspberry and blueberry in the PFAL ${ }^{[5]}$.

\subsection{Method of considerably improving overall monetary productivity}

Even in profitable PFALs in Japan, recent advanced technologies such as artificial intelligence (AI) including deep learning, IoT, continuous plant traits measurement (or phenotyping), solar cells with batteries, OMICS (genomics, metabolomics, proteomics, transcriptomics, etc.) and cultivars bred specifically for PFALs using DNA markers are rarely implemented as of 2019. Therefore, the productivities could be further improved by introducing such advanced technologies properly.

On the other hand, before introducing such advanced technologies into the PFAL, we need to create a concept and methodology relevant for n-PFAL design and management which are considerably different from those of the design and management of existing PFALs and greenhouses.

\subsection{Resource use efficiency (RUE)}

Resource use efficiency (RUE) is defined as the amount ratio $(\mathrm{kg}, \mathrm{mol}, \mathrm{kW} \cdot \mathrm{h}$, etc.) of a resource element fixed or held in plants or produce to the resource element supplied to the cultivation room in a period of one hour, one day, one week or one cultivation period $^{[3,6]}$. The RUE values for each resource element are strongly related to the resource element productivity. Typical RUE values obtained for PFALs with fluorescent lamps for water, $\mathrm{CO}_{2}$, photosynthetic light energy and electric energy are, respectively, $0.95-0.98,0.87-0.89,0.027$, and $0.07^{[5,6]}$, while those of theoretical maximum values are, respectively, 1.0. 1.0, about $0.10^{[9]}$ and about 0.04 . RUE of inorganic fertilizer would be around 0.85 in case of hydroponic cultivation with a nutrient solution recycling unit.

RUEs of water, $\mathrm{CO}_{2}$ and fertilizer are inherently high in the airtight and thermally insulated PFAL with the hydroponic cultivation units. However, light energy use efficiency (LUE) was only about $1 / 4$ of theoretical maximum value (about 0.1 ) when using fluorescent tubes as light source. This low LUE value suggests that the LUE can be improved further by improving the lighting system using LEDs, environmental factors and lighting strategy. A deeper understanding of the physiological responses to light will facilitate energy savings and provide productivity benefits that have not previously been associated with lighting $^{[10]}$.

Electric energy use efficiency (EUE) is a product of LUE and the conversion factor of electric energy to photosynthetic light energy $\left(C_{e}\right)^{[7]}$. The Ce was improved recently from 0.25 for fluorescent tubes to about 0.35 for LEDs, and will be improved to 0.40 or higher in the near future.

\section{Types and characteristics of plant production and hydroponic systems}

\subsection{Types of plant production systems}

Plant production systems are roughly classified into: 1) open, 2) semi-closed (or semi-open) and 3) closed systems (Figure 2$)^{[3]}$. Semi-closed systems are generally called greenhouses, and closed systems are called indoor or vertical farms. PFALs are one type of closed systems; they are highly airtight and thermally well insulated indoor systems.

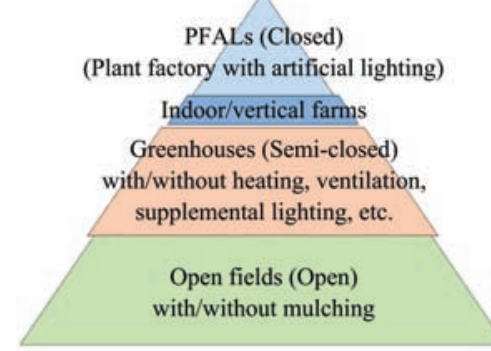

Figure 2 Classification of plant production systems

3.2 Natural stability, buffer capacity and artificial controllability of plant production systems

3.2.1 Characteristics of plant production systems

There are large differences in natural stability, buffer capacity and artificial controllability between open, semi-closed and closed systems (Table 1). Closed systems are characterized by their low natural stability, low buffer capacity and high artificial controllability. The rootzone of open systems needs to be naturally (spontaneous, without a man-made controller) stable with a large volume of fertile soil having high chemical, physical and biological buffer capacities, regardless of the weather or environment outside.

Air temperature and water vapor pressure deficit (VPD), or relative humidity, in open and semi-closed systems are affected considerably by temporal variations in solar radiation flux density among others, because the thermal buffer capacity or heat capacity of air is low due to its low density $\left(1.2 \mathrm{~kg} / \mathrm{m}^{3}\right)$ and low specific heat $(1 \mathrm{~kJ} / \mathrm{kg} \cdot \mathrm{K})$ of room air $\left(25^{\circ} \mathrm{C}\right.$ and $60 \%$ relative humidity). Thus, heat capacity (the product of density and specific heat) of room air is about $1 / 3000$ of water at $25^{\circ} \mathrm{C}$. In addition of thermal buffer capacity, chemical and biological buffer capacities of substrate and nutrient solution can be considered, but their definitions are more complicated than the thermal buffer capacity.

Table 1 Types and characteristics of open- (field), semi-closed (greenhouse) and closed (PFAL) plant production systems

\begin{tabular}{ccccc}
\hline \multirow{2}{*}{ Type } & Natural & $\begin{array}{c}\text { Buffer } \\
\text { stability } \\
\text { capacity }\end{array}$ & $\begin{array}{c}\text { Artificial } \\
\text { controllability }\end{array}$ \\
\hline \multirow{2}{*}{ Open system } & Rootzone & High & High & Low \\
& Aerial zone & Low & Low & Low \\
\hline \multirow{2}{*}{$\begin{array}{c}\text { Semi-closed } \\
\text { system }\end{array}$} & Rootzone & Medium & Medium & Medium \\
& Aerial zone & Low & Low & Medium \\
\hline \multirow{2}{*}{ Closed system } & Rootzone & Low* & Low & High \\
& Aerial zone & Low* & Low & High \\
\hline
\end{tabular}

Note: * Back-up units in case of power supply failure or malfunction of actuators are needed.

3.2.2 Observability, controllability, predictability and reproducibility of n-PFALs

The n-PFAL is a plant production system that aims to achieve the highest productivity, i.e., highest yield and quality, while minimizing resource inputs and emissions of environmental pollutants, based on its high observability, controllability, predictability and reproducibility, using recent advanced technologies such as AI and IoT (Figure 3). The high observability, controllability, predictability and reproducibility of the PFAL are attributable to its high airtightness and thermally well insulated structure. 


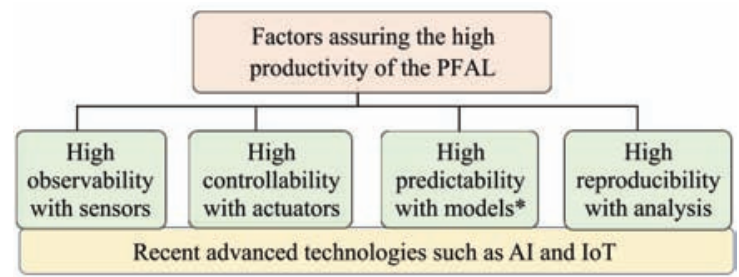

Note: * Mechanistic, multi-variate statistical, behavior (or surrogate) and artificial intelligence (AI) models.

Figure 3 Factors assuring the high productivity of the PFAL, see the text for the definition of the productivity

\subsubsection{Environmental control characteristics of PFALs}

The environmental controllability of airtight and thermally insulated PFAL is high. Low buffer capacities of closed systems are necessary to achieve high artificial controllability using man-made controllers for rootzone and aerial environments, regardless of the weather, to be controlled accurately at time-dependent setpoints of environmental factors. Stable artificial controllability of closed systems with low buffer capacities largely depends on the reliability of its sensors, control software and actuators. The success of PFAL operation largely depends on the controllability and thus reproducibility, which are inherently higher in closed systems than in open and semi-closed systems.

\subsection{Types of hydroponic cultivation systems used in PFALs} and greenhouses

\subsubsection{Types of hydroponic cultivation systems}

In almost all PFALs and some greenhouses, hydroponic cultivation systems (or hydroponic systems) are used to control the rootzone environment, including the nutrient film technique (NFT), deep flow technique (DFT), trickle (drip) irrigation, and ebb and flow systems ( $\mathrm{Lu} \mathrm{Na}$ and Shimamura (Chapter 3) in [11]). Trickle irrigation systems are widely used in rockwool/bag cultivation system in greenhouses, but rarely used in PFALs.

In NFT, DFT and ebb and flow systems, nutrient solution is circulated via a nutrient solution tank (Table 1). Desirable characteristics of the n-PFAL are also shown in Table 2. In NFT and DFT, nutrient solution is continuously supplied to the cultivation beds, while nutrient solution is basically intermittently supplied in trickle and ebb and flow systems. Volume of substrate (medium) is generally smaller in NFT and DFT systems than in trickle and ebb and flow systems. In NFT and DFT systems, chemically inert substrates such as foamed and formed urethane cubes are preferred in PFALs.

Table 2 Types and general characteristics of hydroponic systems used in PFALs and greenhouses, and those of ideal hydroponic systems in PFALs

\begin{tabular}{|c|c|c|c|c|c|}
\hline $\begin{array}{l}\text { Type of } \\
\text { hydroponic } \\
\text { system }\end{array}$ & $\begin{array}{c}\text { Circulation } \\
\text { of } \\
\text { nutrient } \\
\text { Solution }\end{array}$ & $\begin{array}{l}\text { Continuous } \\
\text { supply of } \\
\text { nutrient } \\
\text { solution }\end{array}$ & $\begin{array}{l}\text { Total } \\
\text { volume of } \\
\text { nutrient } \\
\text { solution }\end{array}$ & $\begin{array}{l}\text { Volume of } \\
\text { substrate }\end{array}$ & $\begin{array}{c}\text { Capacity of } \\
\text { nutrient } \\
\text { solution } \\
\text { tank }\end{array}$ \\
\hline NFT & Yes & Yes & Medium & Small & Medium \\
\hline $\begin{array}{l}\text { Trickle } \\
\text { irrigation }\end{array}$ & Yes & $\begin{array}{l}\text { No in most } \\
\text { cases }\end{array}$ & Small & Medium & Small \\
\hline Ebb and Flow & Yes & No & Large & Medium & Large \\
\hline DFT & Yes & Yes & Large & Small & Large \\
\hline $\begin{array}{c}\text { Hydroponics in } \\
\text { n-PFAL }\end{array}$ & No* & $\begin{array}{c}\text { Yes, but at } \\
\text { variable rate }\end{array}$ & Very small & Very small & Very small \\
\hline
\end{tabular}

Note: *No' in case of no drain of used nutrient solution or no accumulation of unused nutrient elements in the substrate.
DFT systems with large volumes of nutrient solution and substrate in the cultivation beds, piping and storage tank have high natural stability due to their high buffer capacities, but have low artificial controllability. This type of hydroponic system is suited to greenhouses with a relatively unreliable controller and/or power supply.

3.3.2 Characteristics of hydroponic systems to be introduced to n-PFALs

In NFT systems, natural stability and buffer capacity are low whereas artificial controllability is high, compared with those of DFT, trickle and ebb and flow systems.

In the n-PFAL, hydroponic systems with a minimum volume of substrate and minimum volume of nutrient solution in the cultivation beds, piping, and nutrient solution tank need to be installed to minimize the buffer capacities and thus maximize the artificial controllability. One-way nutrient solution flow with no drain of wasted nutrient solution and no accumulation of any chemicals/ions in the cultivation beds is an ideal nutrient supply system in the n-PFALs (Table 1).

In NFT and trickle irrigation systems with a minimum volume of substrate, reliable backup units for power supply with batteries, sensors and actuators are indispensable to ensure high artificial controllability of the environment. These can reduce the size, materials and cost of hydroponic systems for closed systems.

3.3.3 Fundamental and potential characteristics of ideal PFALs

The design and management of existing PFALs are considerably influenced by those of existing hydroponic greenhouses which use solar light. However, it is time to think about the design and management of ideal or n-PFALs, based on a new vision, concepts, methodology and technology to maximize the resource and monetary productivities ${ }^{[12,13]}$, considering the basic and potential characteristics of PFALs.

\subsection{Taste and Nutrition of PFAL-grown vegetables}

Taste and nutrition of PFAL-grown vegetables have been improved recently and will be improved year bay year in the forthcoming years. Once PFAL growers find a dataset of the cultivar, environment and cultivation method to grow tasty and nutritious plants, they can reproduce the high-quality produce anytime and anywhere, in principle. This digital dataset of the cultivar, environment and cultivation method can be efficiently shared with many people living in various geographical locations.

On the other hand, the quality of vegetables grown outside under solar light by an expert grower varies year by year mainly due to the changes in weather. The quality and yield of vegetables are also affected by properties of soil and population density of pest insects there.

An organic vegetable grower says that organic vegetables are not always tasty and nutritious, and that the vegetables are delicious and nutritious only when a suitable cultivar is grown by a skillful grower under favorable weather and soil conditions; and they are tasted or cooked at an appropriate time after harvest (often just after harvest). Most vegetables grown in such a way are healthy and are mostly resistant to environmental and biological stresses, so that no pesticide is required.

This is also true for a PFAL grower. Appropriate choices of cultivar and air/rootzone environments are the important factors to grow high-value plants in the PFAL. Taste and nutrition of PFAL-grown vegetables should be better than those of field-and greenhouse-grown vegetables at off-season, and taste and nutrition of greenhouse-grown vegetables are often better than those of field-grown vegetable. 


\section{Fundamental and potential characteristics of ideal PFALs}

4.1 Main uses of plants produced in PFAL

Plants produced in the PFAL can be used for various purposes. Figure 4 shows main uses of plants produced in PFAL. The quality and quantity of produce demanded by crop producers, buyers and/or consumers vary according to the purpose of sale, purchase or use, but higher quality and lower costs are always required. Such demand is partially satisfied if all parts of the plants can be used, marketed and/or sold, with virtually no plant residue or loss of plants produced. The economic value, or value per $\mathrm{kg}$ of produce used, is maximized when the quality of all parts of all plants is highest. This final goal needs to be kept in mind when designing and managing ideal PFALs.

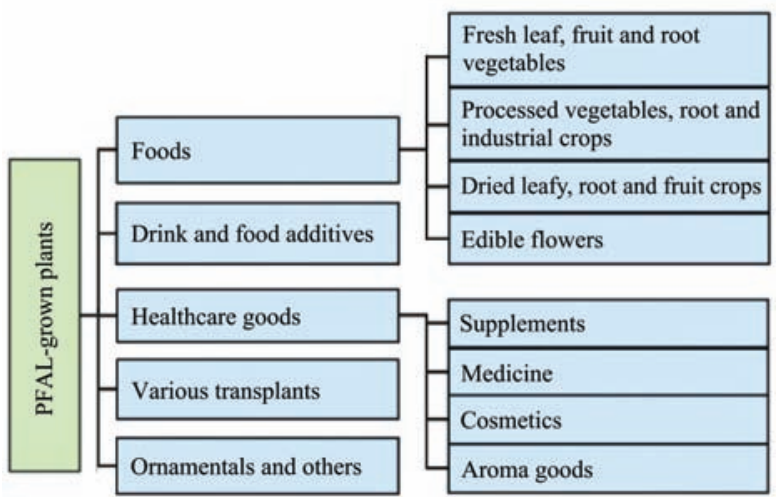

Figure 4 Main uses of plants produced in PFAL

\subsection{Practical and essential benefits of PFALs}

\subsubsection{Practical benefits}

Practical benefits of fairly airtight and thermally insulated PFALs include: 1) the environment inside the cultivation room is not influenced by the weather, 2) no condensation occurs on the inside walls, 3) no insects and dust enter the cultivation room through the windows on the walls, and 4) high resource use efficiencies (Figure 1).

It should be noted that the relative humidity in the cultivation room reaches almost $100 \%$ during dark periods. To avoid this high humidity, in most PFALs, two-thirds of lamps are alternately turned on all day. Then, air conditioners are operated all day to keep room air temperature at preferable levels by removing the heat generated by the lamps. The air conditioners remove not only sensible heat to lower the room air temperature, but also remove latent heat (water vapor) and dehumidify the room air. In this way, relative humidity is kept at preferable levels all day ${ }^{[3,11]}$.

4.2.2 Essential benefits

It should be noted that the essential benefits of fairly airtight and thermally insulated PFALs are ${ }^{[3,6]}$ :

1) All the hourly supply rates of resource elements (electricity, water, $\mathrm{CO}_{2}$, number of seeds and other consumables) to the cultivation room in the PFAL can be measured accurately, and working hours, operation time of each machine, and environmental factors are measured accurately.

2) All the hourly production rates of marketable produce, plant residue (unmarketable produce), wastewater, and used substrates can be measured accurately.

3) Hourly resource use efficiency (RUE) can be estimated for each resource element.

4) Hourly net photosynthetic rate and water uptake rate of plants in the cultivation room can be estimated.
5) Hourly energy use efficiency (or coefficient of performance (COP) of air conditioners) can be estimated.

By analyzing and visualizing the above data, RUE and plant growth rate and thus the productivities can be improved successively.

\subsection{Fundamental characteristics of ideal PFALs and ideas for actualizing the ideal PFALs}

Ideal PFALs for maximizing productivity, i.e., highest yield and quality while minimizing resource inputs and emissions of environmental pollutants, are characterized by the factors shown in Table 3, and some fundamental ideas for the design and management of ideal PFALs are given in Table 4.

Table 3 Desired fundamental characteristics of ideal PFALs

Environmental and plant growth uniformities

No. 1 All light energy emitted by lamps is received by leaves and distributed equally to all parts of all leaves.

All aerial and rootzone environmental factors including air current speed

No. 2 and nutrient solution flow speed are spatially uniform in the plant canopy, aiming at uniform growth of all seeds and plants.

Aerial and rootzone environmental factors are controlled so that light

No. 3 energy is converted at its maximum efficiency to the chemical energy of carbohydrates in leaves.

No. 4 Spatial plant density and growth rate are uniform and highest at any growth stage.

High resource use efficiency

No. 5 Water and $\mathrm{CO}_{2}$ use efficiencies are $100 \%$, respectively, by their recycling use.

No. 6 Nutrient element use efficiency is $100 \%$ without nutrient solution recycling.

No. 7 Use of substrates and other supplies is minimized or recycled, to minimize waste production.

High controllability of light environmental and plant physiological factors

Light quality, flux density, lighting cycle and direction are optimized by time of day and passage of days, cultivar, purpose of production and cost of lighting to maximize a multi-objective function, considering the

No. 8 of lighting to maximize a multi-objective function, considering the growth are promoted in the first half of growth, and chemical composition and morphological changes are enhanced in the second half.

In addition to photosynthesis and photomorphogenesis, phototropism

No 9 (heliotropism), biological clock, gravitropism, thermoperiodism and some plant physiological disorders such as tipburn and intumescence are important factors to be controlled.

Table 4 Fundamental ideas for the design and management of ideal PFALs

No. 1 Light is dynamically provided downwards, sideways and upwards within and/or from outside of the canopy.

No. 2 Air is provided upwards, sideways and/or downwards within and/or from outside of the canopy.

No. 3 High-quality seeds are carefully selected and grown in spatially uniform environments.

No. 4 All transpired water vapor is condensed by air conditioners for reuse. All $\mathrm{CO}_{2}$ supplied and respired by plants is absorbed by plants under light.

The time course of each nutrient element ion supply rate to cultivation beds is controlled considering the plant growth/production schedule.

No. 5 Total ion concentration or EC (Electric conductivity) in nutrient solution is not controlled. Namely, the supply rate control is preferred to the concentration control.

Minimum amounts of supports (substrate) and other consumables are

No. 6 used. All consumables are biodegradable or chemically/biologically inert.

No. 7 The cultivation room can be scaled up with minimum changes.

No. 8 Automatic handling units (seeding, spacing, transportation, etc.) are installed (see Table 6 as an example).

No. 9 Units for smart lighting, phenotyping and data warehouse are installed. 


\subsection{Additional explanations to Tables 3 and 4}

(1) No. 1 in Table 3: In ideal PFALs, almost all light energy emitted by lamps is absorbed equally by all parts of all leaves within the plant canopy, although a small fraction of light energy is unavoidably absorbed by petioles, stems, etc. This ideal lighting condition can be realized by arranging light sources around and inside the plant canopy to provide light from above, below and the sides.

In the case of headed lettuce, cabbage and Chinese cabbage, a green-rich light can be provided from their surroundings to increase chlorophyll and ascorbic acid concentrations because green light penetrates inside crisp heads ${ }^{[14]}$. Also, a green-rich point light source can be inserted into a central part of the head at a later plant growth stage or after harvest to provide light from the inside.

Under downward lighting conditions, on the other hand, leaves at an upper level receive more light energy than those at lower levels, especially in a densely populated plant canopy (e.g., [15]). In this case, the photosynthetic capacity of lower shaded leaves decreases with time due to adaptation to the shaded condition.

Furthermore, there is a three-dimensional spatial variation of light quality within the plant canopy. This is because over $95 \%$ of blue $(400-500 \mathrm{~nm})$ and red light $(600-700 \mathrm{~nm})$ is absorbed, around $20 \%$ of green light $(500-600 \mathrm{~nm})$ is transmitted or reflected, and about $80 \%$ of far-red light $(700-800 \mathrm{~nm})$ is reflected or transmitted by a horizontal green leaf ${ }^{[9]}$. Thus, under downward lighting, the percentages of green and far-red light in a densely populated canopy increase with increasing depth of the plant canopy.

(2) No. 2 in Table 3: In ideal PFALs, aerial and rootzone environmental factors including air current speed and nutrient solution flow speed within the plant canopy are spatially uniform and each environmental factor is controlled optimally to maximize the light energy use efficiency of each leaf and thus of the plant canopy at the lowest total cost for aerial and rootzone environmental control. Under such environmental conditions, the photosynthetic capacity and thus net photosynthetic rate of all leaves within the plant canopy are the same with no or minimum senescence of leaves.

On the other hand, in conventional PFALs, air current speed or $\mathrm{CO}_{2}$ and water vapor gas diffusion coefficients in the plant canopy are significantly lower at lower leaves than at upper leaves, thus restricting the rates of net photosynthesis and transpiration of lower leaves even under the same PPFD conditions.

All seeds and transplants are grown to harvestable plants, and all parts of all plants can be used, marketed and/or sold, resulting in no plant residue including physically or physiologically damaged leaves and useless roots. If the leafy or aerial parts of plants are usable, the dry weight of roots needs to be minimized provided the roots do not restrict the growth of aerial parts. The weight percentage of roots over a whole plant is $10 \%-15 \%$ in existing PFALs, but should be $5 \%$ or lower in the n-PFALs. Also, the size and weight of plants grown in the n-PFALs should be uniform ${ }^{[1]}$.

(3) No. 5 in Table 4: All nutrient element ions are supplied into cultivation beds with water hourly or several times a day through one-way (non-circulating) tubing so that they are all absorbed by plants within one day, resulting in nutrient use efficiency of almost $100 \%$. By using this hydroponic system, the nutrient solution volume required in the PFAL is minimized. To realize this hydroponic system, the desirable uptake rate of each nutrient ion by plants needs to be estimated using the plant growth models. Supply of ions that are absorbed only a little $\left(\mathrm{Cl}^{-1}, \mathrm{Na}^{+}\right.$, etc.) by plants or are unnecessary for plants is restricted. Accumulation of undesirable organic acids and volatile organic compounds emitted from roots needs to be avoided.

\subsection{Issues to be solved to design and operate sustainable PFALs}

There are three issues to be solved for the design and operation of sustainable PFALs ${ }^{[16]}$ : to reduce $\mathrm{CO}_{2}$ emissions and fossil fuel energy consumption, it is necessary to use much smaller amounts of 1) iron/steel/aluminum elements for constructing PFALs, 2) potassium and phosphate fertilizers also for preserving their finite natural resources (rock phosphate and potash ore), and 3) electricity generated by fossil fuels and/or nuclear power (use natural energy such as solar energy, wind power, biomass energy for generation of electricity). The consumption of the fertilizer and electricity can be reduced by, respectively, improving the fertilizer and electricity use efficiencies.

\section{Perspectives of the next-generation PFALs - Overview $^{[1,13]}$}

\subsection{Scheme of the next generation PFAL (n-PFAL)}

For the n-PFAL, the development and improvement of cultivars, cultivation units, environmental control units, human resource programs and phenotyping units, all of which are closely linked, are conducted concurrently during production (Figure 5).

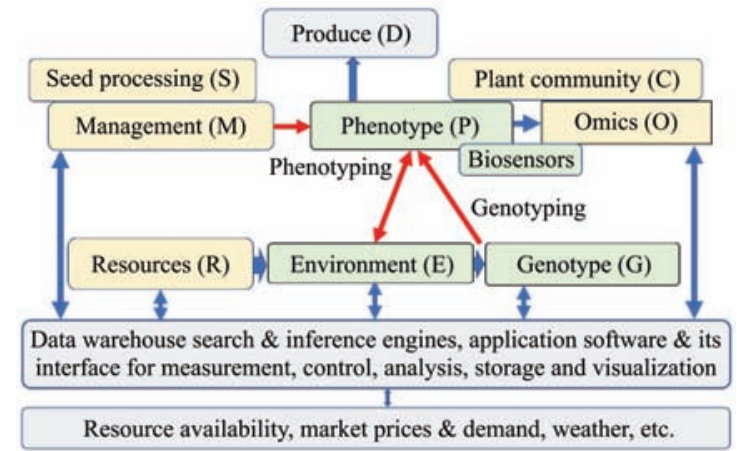

Figure 5 Scheme for production process and environmental control, productivity improvement and breeding in the next-generation PFAL (modified from [1])

In this sense, the n-PFAL is data-driven and evolutional. The collection and analysis of data (including a large amount of image data) for the production process and environmental control, productivity improvement and breeding are a core part of the n-PFAL. In the n-PFAL, in addition to $\mathrm{S}$ and $\mathrm{G}$, time-series data of $\mathrm{P}, \mathrm{E}, \mathrm{M}, \mathrm{R}, \mathrm{D}$ and $\mathrm{O}$ are collected and stored in a data warehouse networked locally and globally. Continuous phenotyping or continuous measurement of plant traits $(\mathrm{P})$ is challenging, whereas continuous measurement of $\mathrm{E}, \mathrm{M}, \mathrm{R}$ and $\mathrm{D}$ is relatively easy.

Once time-series datasets of (P, E, M, R, D, O, C, S, G) are obtained, $\mathrm{P}$ can be expressed as $\mathrm{P}=$ Function (E, M, R, D, O, C, S, G) and $\mathrm{E}$ can be expressed as $\mathrm{E}=$ Function $(\mathrm{P}, \mathrm{M}, \mathrm{R}, \mathrm{D}, \mathrm{O}, \mathrm{C}, \mathrm{S}, \mathrm{G})$, using the deep learning method in AI technology. This means that $\mathrm{P}$ under conditions of $\mathrm{E}, \mathrm{M}, \mathrm{D}, \mathrm{S}$ and $\mathrm{G}$ can be predicted, and a favorable $\mathrm{E}$ can be found to obtain $\mathrm{P}$ under given $\mathrm{G}, \mathrm{M}$ and $\mathrm{D}$. Recently, explainable AI (or XAI) technology is making a progress $^{[17]}$; especially explainable machine learning system which produces more explainable models, while maintaining a high level of learning performances or prediction accuracy. Figure 6 shows the relational diagram of technologies for efficient production and breeding of indoor and outdoor plants.

In addition, there has been increasing interest recently in data fusion of information technology (IT) with operation technology 
(OT) in manufacturing companies. At the same time, data visualization, multi-variate data analysis and data sharing is attracting an attention in a factory where a huge amount of data are collected and analyzed. These technologies will be integrated into the n-PFAL technology.

It is noted that the n-PFAL can be used not only to breed indoor crops, but also to breed outdoor crops. Furthermore, it can be used for seed propagation of indoor and outdoor crops, in addition to transplant (seedling, micropropagated plantlets) production of outdoor plants. Figure 6 shows the schematic relational diagram of technologies for efficient production and breeding of indoor and outdoor plants.

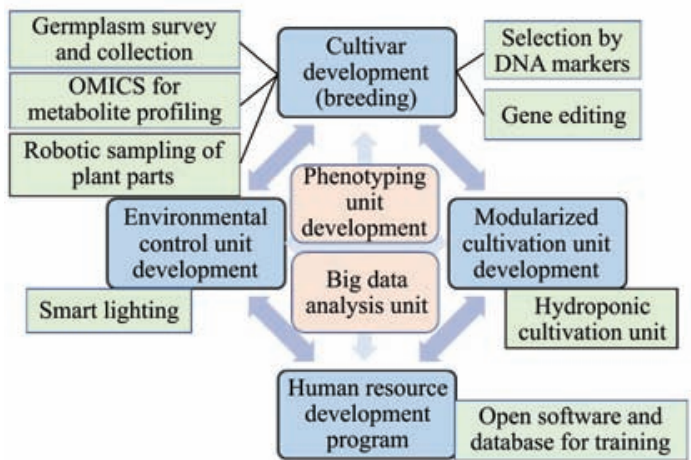

Figure 6 Relational diagram of technologies required for efficient production and breeding of indoor and outdoor plants using PFALs

\subsection{Phenotyping}

Phenotyping, a key technology in the n-PFAL, is defined in this paper as methodologies and protocols to measure a plant-specific trait non-invasively, mostly using various kinds of cameras, ranging from the cellular level to canopy level, related to plant structure and function (partly cited from [18]). Table 5 is an example of plant traits affecting the economic value of vegetables. The phenotype of plants in the PFAL is affected by many factors (Figure 7). Phenotyping in the n-PFAL is conducted at various plant growth stages during plant production (Figures 8 and 9).

Table 5 Selected plant traits affecting the economic value of vegetables

\begin{tabular}{|c|c|c|}
\hline & Factors & Typical trait variables \\
\hline 1 & $\begin{array}{l}\text { Shape, color, } \\
\text { texture }\end{array}$ & $\begin{array}{l}\text { Plant height, leaf shape \& thickness, leaf area index (LAI), } \\
\text { stem/internode length, pigment formation, appearance }\end{array}$ \\
\hline 2 & $\begin{array}{l}\text { Functional } \\
\text { components }\end{array}$ & $\begin{array}{l}\text { Minerals, antioxidant substances such as vitamins, } \\
\text { polyphenols, carotenoids and polysaccharides }\end{array}$ \\
\hline 3 & $\begin{array}{l}\text { Physiological } \\
\text { disorders }\end{array}$ & $\begin{array}{l}\text { Tip burn, intumescence, white/black spots due to } \\
\text { micronutrient deficiencies }\end{array}$ \\
\hline 4 & Taste, flavor & $\begin{array}{l}\text { Sugar, polysaccharides, aromas, amino acids, proteins, } \\
\text { lipids, } \mathrm{NO}_{3}^{-}, \mathrm{K}^{+} \text {, bitterness }\end{array}$ \\
\hline 5 & Mouth feeling & Turgor pressure, cell wall thickness, smoothness \\
\hline 6 & Shelf life & Colony formation unit of microorganisms per gram \\
\hline
\end{tabular}

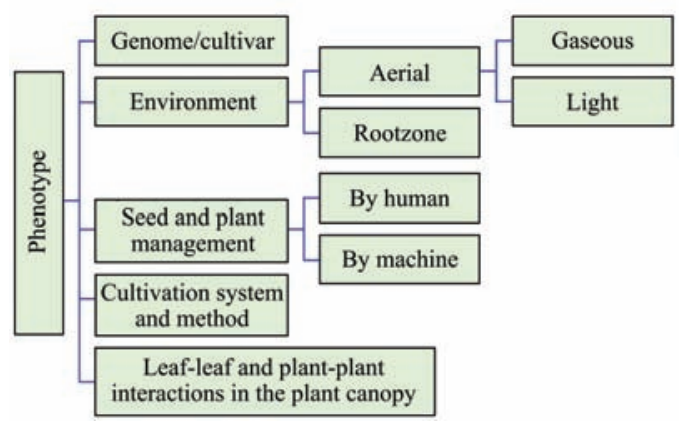

Figure 7 Factors affecting plant phenotype in the PFAL

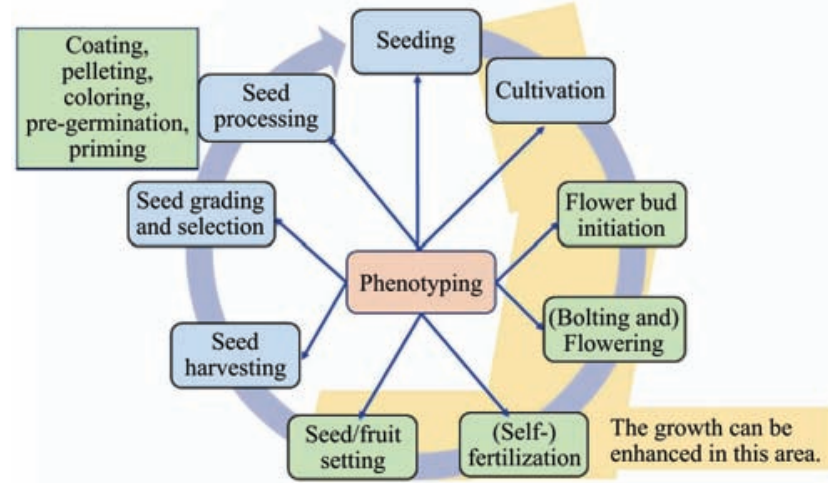

Figure 8 Phenotyping cycle for seed production and breeding

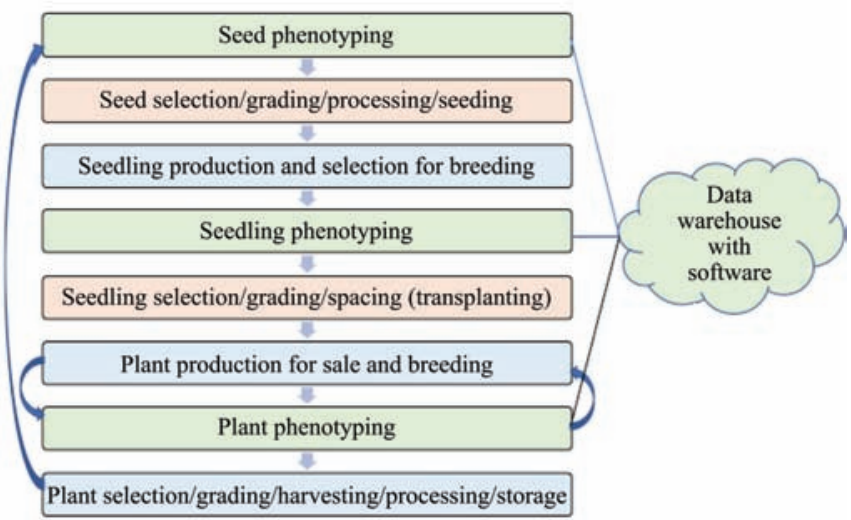

Figure 9 Phenotyping for plant production and breeding in the n-PFAL

\subsection{Breeding of vegetables in the PFAL}

The n-PFAL can be used to accelerate breeding outdoor/ indoor crops using the automatic phenotyping units under controlled environment. As shown in Figure 5, contributions of genetic, environmental and management factors causing variations in plant phenotype are analyzed using the data in data warehouse.

Cultivars currently grown in existing PFALs are all bred to suit cultivation outdoors or in greenhouses. The most important traits to be considered in the breeding of plants for field and greenhouse cultivation are disease resistance and environmental stress resistance. Then, types of resistance required for outdoor and greenhouse cultivation depend on the locality (climate/season/ weather, soil properties, water availability, ecosystems nearby, etc.).

On the other hand, since PFALs are clean and almost pathogen-free, disease resistance is not required in principle. Since plants in the PFAL are grown under controlled environments, environmental stress resistance is not required either, although plants are often grown intentionally under environmentally stressful conditions to enhance the production of secondary metabolites.

Cultivars that grow fast without any physiological disorder such as tip burn and intumescence under high $\mathrm{CO}_{2}$ concentration and low photosynthetic photon flux density have not yet appeared on the market. Such cultivars would be of high value in the PFAL industry ${ }^{[1]}$. In addition to leafy vegetables, efforts are being made to improve the monetary and resource productivities of medicinal plants, tomato, strawberry, blueberry, etc. In these cases, the plant traits required for growing in PFALs are considerably different from those for outdoor and greenhouse cultivation. For example, self-pollination or parthenocarpy of strawberry, tomato, etc. is an important trait when they are grown in the PFAL. Dwarf root vegetables such as carrot, turnip and radish would attract 
consumers if their leafy parts were as tasty as the roots. Medicinal plants with enhanced functional components suited to production in the PFAL will create a huge market in the future.

As an example, Table 6 shows desired traits for automated cultivation of tomato plants in multi-tier (layer) PFALs $(50-60 \mathrm{~cm}$ vertical distance between layers). Figure 10 is a maginary scheme showing dwarf tomato cultivation in a 4-tier PFAL, and a dwarf cherry tomato plants (leaves were removed before taking the photo) grown horizontally on the cultivation panels of the cultivation bed.

Table 6 Desired traits of tomatoes to be grown from seeding to harvest on a moving cultivation belt in an automated multi-tier PFAL

\begin{tabular}{|c|c|}
\hline No. 1 & $\begin{array}{l}\text { Dwarf (around } 40-50 \mathrm{~cm} \text { high) with short internodes under no far-red } \\
\text { light }\end{array}$ \\
\hline No. 2 & Self-pruning (or determinate) with no lateral shoots \\
\hline No. 3 & Parthenocarpy, or self-pollination for fertilization \\
\hline No. 4 & No senescence of lower leaves by sideward and/or upward lighting \\
\hline No. 5 & $\begin{array}{l}\text { No growth retardation even at high density under controlled } \\
\text { environments }\end{array}$ \\
\hline No. 6 & Simultaneous fruit maturation for harvesting all at once \\
\hline No. 7 & Easy dropdown of mature fruits by shaking the plants (upside down) \\
\hline No. 8 & High translocation percentage of carbohydrates (sugar) in leaves to fruits \\
\hline No. 9 & $\begin{array}{l}\text { High carotene, vitamin } \mathrm{C} \text { and sugar content under controlled } \\
\text { environment }\end{array}$ \\
\hline
\end{tabular}
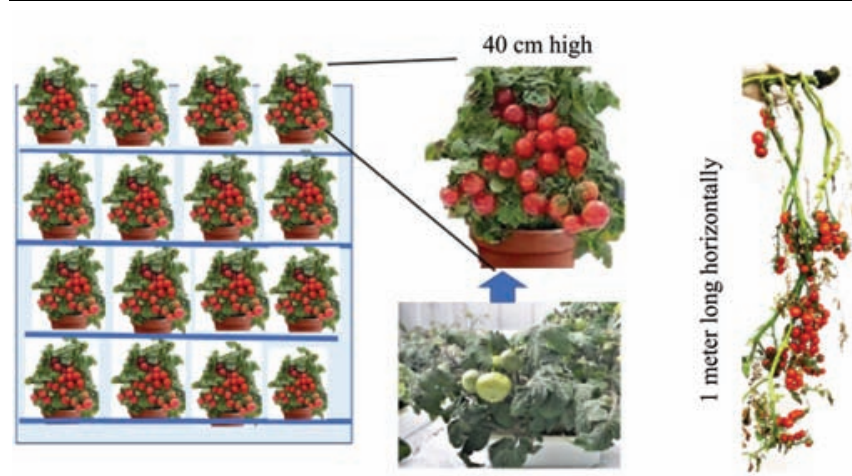

Figure 10 Imaginary scheme showing dwarf tomato cultivation in a 4-tier PFAL (left and middle), and a dwarf cherry tomato plant without leaves grown horizontally on the cultivation bed of PFAL (right) (Photo by O. Nunomura)

\section{Contribution of PFALs to the Sustainable Development Goals (SDGs)}

In 2015, more than 190 world leaders committed to 17 Sustainable Development Goals (SDGs) that are a universal call to action to end poverty, protect the planet and ensure that all people enjoy peace and prosperity by $2030^{[2]}$. In this section, we discuss how PFALs can contribute to achieving those goals, and why PFALs are an efficient means of achieving them, keeping in mind that: 1) PFAL technology using light emitting diodes (LEDs) has just emerged and is still at the initial stage, and 2) efforts to apply PFAL technology to achieve the SDGs have just started. Thus, the descriptions in this section are merely a stepping stone for further discussion.

It is noted that: 1) PFALs can be efficiently used by connecting them with a smartphone to share information publicly via the Internet; 2) Creative and collaborative ideas, which often emerge during workshops, are essential to find practical ways to use PFALs to help achieve the SDGs; and 3) PFALs can be efficiently used when the key potential characteristics of PFALs are well understood with respect to high yield and quality, resource-saving, environmental conservation and quality of life.

Goal 1. No poverty: A PFAL can be built anywhere in the world - in hot, cold, dry and wet regions - to produce high-quality functional plants such as vegetables, medicinal plants and ornamental plants (excluding staple crops such as wheat and rice) all year around, as well as for purposes such as seedling production using minimum land/floor area and other resources such as water and fertilizer.

No heating is required even on cold winter nights when more than half of the lamps are turned on for lighting because 1) PFALs are thermally well insulated and 2) the heat generated by the lamps is more than enough to keep the air temperature of the thermally insulated and air tight cultivation room at $25^{\circ} \mathrm{C}$ when outside temperature of $-40^{\circ} \mathrm{C}$ or so. Instead, cooling is required all day and all year round when the lamps are turned on. The cooling cost accounts for around $20 \%$ of the total (lighting, cooling, pumping, etc.) electricity cost in hot regions and $10 \%-15 \%$ in cold regions ${ }^{[3,6]}$. Total electricity cost accounts for about $20 \%$ of the total production cost in Japan.

A non-profit or public-supported organization could lend citizens and farmers a mini-PFAL with a floor area of $5-10 \mathrm{~m}^{2}$ or money for renting a mini-PFAL for starting a small personal, family or group business to help end poverty. The mini-PFAL looks like a small windowless warehouse, and can be built in residential areas. The annual productivity of leaf lettuce in the mini-PFAL is about $90 \mathrm{~kg} / \mathrm{m}^{2} \cdot \mathrm{a}$ if operated by a qualified professional grower. However, it would be around $10-20 \mathrm{~kg} / \mathrm{m}^{2} \cdot \mathrm{a}$ if operated by a beginner.

The initial investment cost of a PFAL per unit land area is about 10 times higher than that of a greenhouse with environment control units and is around 100 times higher than that of an open field equipped water irrigation devices and standard cultivation machines. However, the initial investment cost per $\mathrm{kg}$ of produce for a PFAL, greenhouse and open field is almost the same because the productivity per unit land area is around 10 times and 100 times higher for the PFAL than the greenhouse and the open field.

The mini-PFAL is also called a cultivation system module (CSM) with a floor area of around $10-20 \mathrm{~m}^{2[1]}$, and any size of PFAL (medium or large PFAL) can be constructed with multiple CSMs. This scalable or expandable characteristic of the PFAL using CSMs can play an important role in ending poverty and improving incomes step by step.

Goal 2. Zero hunger: The mini-PFAL can be a sustainable plant production system operated by electricity generated from natural energy for home use to end hunger, to achieve food security and to improve nutrition. Operation and maintenance manuals and other information can be obtained free of charge from open databases and self-learning systems via the Internet. The mini-PFAL can be used as a small personal/family business or for self-consumption at home.

Measurement, control and maintenance of the PFAL can be conducted using a smartphone after downloading software free of charge. The land area required for vegetable production is about one-hundredth that of open fields, and there is no damage by weather, pest insects, worms or wild animals. The PFAL can be locked for safety when necessary. A power-cut for about 15-20 h would not damage the plant growth significantly provided a minimum battery unit for data collection and water pump operation is installed.

A prefabricated PFAL with floor area of 5-20 $\mathrm{m}^{2}$ composed of natural (e.g., solar) energy-powered cultivation system modules 
(CSMs) can be built and operated within a few months from the start of on-site operations anywhere such as a refugee camp or disaster area, locally producing and delivering a large amount (e.g., $100-500 \mathrm{~kg}$ ) of fresh, tasty, nutritious and ready-to-eat-withoutwashing vegetables. After sowing seeds, sprouts can be harvested within one week, microgreens within 2 weeks, baby leaf greens within 3 weeks, leaf lettuce plants (100 g per head) within 5 weeks. Once these prefabricated CSMs are developed, the initial investment cost will be considerably reduced.

Goal 3. Good health and well-being for people: Growing plants for food and other purposes is often enjoyable and has a healing effect, and generally improves quality of life at all ages. Besides, the PFAL provides a space for communication among locals ${ }^{[3]}$. By using software downloaded for free, appropriate environmental setpoints, species, cultivars and cultivation methods can be obtained, producing plants suitable for people having problems with kidney, blood pressure, diabetes, or other diseases. This approach brings to mind the proverb 'Do not give fish but teach how to fish'.

Goal 4. Quality education: By growing plants in the PFAL with a self-learning system, people can learn about basic plant physiology, ecology, recycling of water, $\mathrm{CO}_{2}$, energy and nutrient elements concurrently in an integrated, simplified and understandable form ${ }^{[3]}$. Mechanisms of the PFAL system containing an artificial plant community can be more efficiently learned by using a virtual PFAL system (computer simulation software and peripherals) connected with a corresponding actual PFAL $^{[1]}$. A PFAL with floor area of 0.1-0.5 $\mathrm{m}^{2}$ can be used for educational purposes or for a personal use as a hobby (Chapter 2 by Harper and Chapter 5 by Takagaki, et al. ${ }^{[3]}$ ).

Furthermore, experience and knowledge of using a PFAL helps people understand the essence of more complex natural and artificial open-field ecosystems. On the other hand, PFAL workers and managers need greater skill and deeper knowledge for operations compared with conventional farmers and growers.

Goal 5. Gender equality: Most people enjoy light and safe work in the comfortable, protected environment of a PFAL, regardless of gender, age and physical/mental handicap. Most women and girls will feel less mental and physical stress when working in a PFAL, and will feel gender equality during most working hours. PFAL-grown plants are served to and consumed by people of different genders, ages, health conditions and preferences, so various kinds of workers are necessary to produce various kinds of plants for various kinds of people with different preferences.

Goal 6. Clean water and sanitation: PFALs use water transpired from plant leaves by condensing and collecting water vapor in the cultivation room at the cooling panels of air conditioners to be recycled as irrigation water. Thus, net water consumption for irrigation in a PFAL is about $5 \%$ of that in a greenhous $^{[6]}$. The condensed water is as clean as drinking water if the cultivation room is hygienic. As a result, PFAL-grown pesticide-free vegetables can be eaten in fresh salads without washing with tap water. The PFAL is thus a kind of plant-based water purification system. Plants absorb river, rain or lake water (not clean) through the roots and produce water vapor from their leaves. When condensed at a clean cooling panel, clean and drinkable liquid water is obtained (around 1 liter per $\mathrm{m}^{2}$ of floor area). Under full operation, the PFAL can provide water for drinking and sanitation for people who are starving after a disaster.

Goal 7. Affordable and clean energy: Although not yet commercialized, the n-PFAL with a battery back-up unit will operate using electricity generated only by solar energy, wind power, biomass or geothermal energy. As of 2018, the electricity cost in a PFAL with LEDs accounts for about $20 \%$ of the total production cost ${ }^{[1]}$. The electricity consumption per $\mathrm{kg}$ of produce in the PFAL will be further reduced in the n-PFAL, while the cost of renewable electricity will fall in the coming years.

Goal 8. Decent work and economic growth: The productivity of the n-PFAL will double or triple compared with that of existing PFALs in the next few decades ${ }^{[1]}$ and will contribute to decent work and economic growth. It is expected that people who want to start a small business will be able to rent a mini-PFAL for producing and selling fresh vegetables, medicinal plants and various seedlings as cash crops.

Goal 9. Industry, innovation, and infrastructure: PFALs are an innovative plant production system which promotes inclusive and sustainable industrialization and agriculture. PFAL technology is being developed by integrating various fields of natural and social sciences and technologies. The PFAL business will foster innovation.

Goal 10. Reducing inequalities: PFALs can be built and operated anywhere, regardless of climate, soil and water availability. Since most aspects of PFAL technology are universal and tend to be open-source, PFALs are suited to local production for local production. A PFAL can be built at a local community center or school ${ }^{[3]}$. Thus, PFALs will help reduce income inequality within and among countries.

People living in remote regions struggle to transport and sell their heavy fresh produce in large cities. People living in cold and hot regions struggle to grow plants for sale in greenhouses and open fields. Instead, they could use PFALs to grow medicinal plants all year round and dry them on site for sale as ingredients for medicine, cosmetics, seasonings and drink/food additives, and could transport the dried produce to buyers every several months when convenient.

Goal 11. Sustainable cities and communities: It should be noted again that PFALs with growing plants are $\mathrm{CO}_{2}$-aborbing ecosystems. By integrating PFALs with $\mathrm{CO}_{2}$-emitting biological systems such as mushroom and aquaculture facilities, or other $\mathrm{CO}_{2}$ emitting systems such as office buildings, the resource use efficiency and sustainability of PFALs and other biological systems can be improved ${ }^{[8]}$, making cities and human settlements inclusive, safe, resilient, and sustainable.

PFALs consume electricity mostly at night and in the early morning and late evening when electricity consumption in office buildings and homes is lower ${ }^{[3]}$. Accordingly, the electric power network can be developed to share the generated electricity optimally with homes, offices, industries and businesses whether power plants are operating normally or abnormally in an emergency.

Goal 12. Responsible consumption and production: PFALs produce plants and consume resources as scheduled considering both resource availability and demand in the region. Thus, sustainable and responsible consumption and sustainable production can be relatively easily ensured. Local production for local consumption minimizes the loss of produce during transportation, storage and handling, and prolongs shelf life due to the cleanness (low microorganism population) and less physical damage of produce. Local people tend to try to minimize vegetable and food waste when they know who, how and where it was produced.

Goal 13. Climate action: The negative impact of climate 
change on plant productivity will be drastically reduced by using n-PFALs. $\mathrm{CO}_{2}$ emission per $\mathrm{kg}$ of produce in PFALs has been reduced in recent years and will be much lower in n-PFALs.

On the other hand, $\mathrm{CO}_{2}$ emitted during the manufacture of iron, cement and aluminum used as structural components of PFALs needs to be reduced. Reinforced wooden structural components need to be used more for the PFALs and cultivation racks ${ }^{[16]}$. Biodegradable plastics and paper bags need to be used more for the cultivation trays and panels. The plant residue produced in PFALs needs to be reduced and/or recycled on site.

Goal 14. Life below water: PFALs constructed below water and underground can be more sustainable than those built above ground. On the other hand, aquaponics, a combination of aquaculture and hydroculture, can be constructed to use fish waste as fertilizer for plants. Since both PFALs and aquaponics are closed systems, they do not hinder the conservation and sustainable use of the oceans, seas and marine resources.

Goal 15. Life on land: For leaf vegetable production, the PFAL uses less than $1 \%$ of the area of open fields and around $10 \%$ of that of greenhouses. Thus, by using PFALs, more land can be used for conserving natural ecosystems with improved biodiversity than using open fields and greenhouses for vegetable production, while people can enjoy fresh vegetables grown nearby.

The n-PFAL is a powerful method of producing millions or billions of high-quality (disease- and insect-free, with high resistance to environmental stress) seedlings for forestation and for preventing desertification, thus halting and reversing land degradation and biodiversity loss. Seedlings can be produced on site in n-PFALs where the climate and soil are generally inappropriate for producing high-quality seedlings in greenhouses and open fields.

Goal 16. Peace, justice and strong institutions: $A$ n-PFAL is composed of multiple cultivation system modules (CSMs) and thus is scalable (expandable). The smallest n-PFAL is a CSM itself. This characteristic of n-PFALs is beneficial to promote peaceful and inclusive societies stepwise for sustainable development, provide access to justice for all and build effective, accountable and inclusive institutions at all levels.

Goal 17. Partnerships for the goals: Since most aspects of PFAL technology are universal and describable, general information on PFALs can be shared via the Internet by means of simultaneous interpretation software with people living anywhere in the world. An organization can be developed to strengthen the means of implementation and revitalize the global partnership for the sustainable development of PFALs.

\section{Conclusions}

This paper has mainly set out the author's views on several issues relating to next-generation plant factories with artificial lighting (n-PFALs). Research and development on n-PFALs has only just started. Both a broad perspective and sharp vision are needed, as well as the creativity of people who are interested in solving mutually conflicting issues concerning food, the environment, resources, and quality of life.

Almost all aspects of any basic science, engineering and technology are neutral. On the other hand, most subjects in applied science, engineering and technology are developed with certain goals at the outset, although some of them are applied in various fields later.

PFAL technology is an applied technology, and has pros and cons, positive and negative aspects, potential and challenges/limitations, risks and opportunities, and successes and failures. Thus, a clear vision, mission and methodology for developing n-PFALs which contribute to achieving the SDGs are indispensable. To achieve the SDGs, further discussion on the vision, mission, and R\&D of the $\mathrm{n}-\mathrm{PFAL}$ is needed.

\section{Acknowledgements}

The author would like to thank Yutaka Shinohara, Toru Maruo, Toshitaka Yamaguchi, Mieko Kasai and Eri Hayashi for their valuable and critical advice and comments during the preparation of this manuscript. The author would also like to thank Dongxian He for her providing an opportunity to write this manuscript.

This manuscript was presented at 2019 International Symposium on Environment Control Technology for Value-added Plant Production hold in Beijing from Aug. 27-29, 2019.

\section{[References]}

[1] Kozai T. Smart plant factory: The next generation indoor vertical farms. Springer, 2018; 456p.

[2] Seth N, Suazo M A. SDGs (Sustainable Development Goals): Main contributions and challenges. United Nations Institute for Training and Research (UNITAR) and Center of Ibero-American Studies, University of Rey Juan Carlos, 2019; 196p.

[3] Kozai T, Niu G, Takagaki M. Plant Factory: An indoor vertical farming system for efficient quality food production. Academic Press, 2015; 405p.

[4] Ijichi H. Chapter 3 plant factory business - current status and perspective of plant factory business. NAPA research report, 2018; pp.58-80.

[5] Kozai T, Uraisami K, Kai K, Hayashi E. Some thoughts on productivity indexes of plant factory with artificial lighting (PFAL), Proc. of International Symposium on Environment Control Technology for Value-added Plant Production, Beijing, China. Aug. 27-30, 2019.

[6] Kozai T. Resource use efficiency of closed plant production system with artificial light: Concept, estimation and application to plant factory. Proceedings of the Japan Academy, Ser. B 89(10), 2013; pp.447-461.

[7] Kozai T. Improving light energy utilization efficiency for a sustainable plant factory with artificial light, Proc. of Green Lighting Shanghai Forum, 2011; pp.375-383.

[8] Kozai T, Fujiwara K, Runkle E. LED lighting for urban agriculture. Springer, 2016; 454p.

[9] Taiz L, Zeiger E. Plant physiology. Fourth edition. Sinauer Associates, Inc. MA, USA, 2006; 763p.

[10] Pattison P M, Tsao J Y, Bugbee B. LEDs for photons, physiology and food. Nature, 2018; 563: 493-500.

[11] Kozai T. Benefits, problems and challenges of plant factories with artificial lighting (PFALs): a short review. Acta Horticulturae (GreenSys 2017), 2018; pp.25-30.

[12] Kozai T, Hayashi E, Amagai Y. Plant factories with artificial lighting (PFALs) towards sustainable plant production. Acta Horticulturae (IHC 2018), 2019. (in press)

[13] Kozai T, Amagai Y, Hayashi E. Towards sustainable plant factories with artificial lighting (PFALs). in Chapter 6: Achieving Sustainable Greenhouse Cultivation. Eds: L. Marcelis and E. Heuvelink), Burleigh Dsugureta odds Science, 2019.

[14] Saengtharatip S, Goto N, Kozai T, Yamori W. Green light penetrates inside crisp head lettuce leading to chlorophyll and ascorbic acid content enhancement. S18 on Soilless Culture, 30th IHC 2018, Istanbul, Turkey, Acta Horticulturae, 2019. (in press)

[15] Oikawa T. Light regime in relation to plant population geometry III Bot. Mag. Tokyo. 2018; 90: 301-311.

[16] Kikuchi Y. Life cycle assessment (Chapter 24). in Plant factory: An indoor vertical farming system for efficient quality food production.(Eds: Kozai T, Niu G, Takagaki M.), Academic Press, 2015. 321-329.

[17] Samek W, Montavon G. Explainable AI: Interpreting, explaining and visualizing deep learning (Lecture Notes in Computer Science). Springer, 2019; 435p.

[18] Kumar J, Pratap A, Kumar S. Phenomics in crop plants: Trends, options and limitations. Springer, 2015; 296p. 